\title{
PENERAPAN LOGIKA FUZZY PADA SISTEM KELAYAKAN TANAH SAWAH BERDASARKAN PH DAN SUHU TANAH
}

\author{
Susilawati $^{1^{*}}$, Adhi Rizal ${ }^{2}$, Asep Jamaludin ${ }^{3}$ \\ ${ }^{1}$ Teknik Informatika, Fakultas Ilmu Komputer, Universitas Singaperbangsa Karawang, J1. H.S Ronggo Waluyo, Karawang, 41361. Indonesia. \\ ${ }^{2}$ Teknik Informatika, Fakultas Ilmu Komputer, Universitas Singaperbangsa Karawang, J1. H.S Ronggo Waluyo, Karawang, 41361. Indonesia. \\ ${ }^{3}$ Teknik Informatika, Fakultas Ilmu Komputre, Universitas Singaperbangsa Karawang, J1. H.S Ronggo Waluyo, Karawang, 41361. Indonesia. \\ *e-mail: susilawati.sobur@staff.unsika.ac.id
}

\begin{abstract}
ABSTRAK
Salah satu faktor yang dapat mempengaruhi pertumbuhan padi adalah tingkat kesuburan tanah. Semakin tinggi tingkat kesuburan tanah, maka keberhasilan budidaya padi akan semakin meningkat. Walaupun demikian, terdapat beberapa faktor penyebab rendahnya produktivitas tanaman padi. Namun, diantara beberapa faktor tersebut, suhu dan pH merupakan dua faktor utama penyebab kegagalan budidaya padi. Hal ini disebabkan karena suhu sangat berpengaruh terdapat pertumbuhan hama, sedangkan $\mathrm{pH}$ berfungsi agar unsur hara dalam tanah dapat dengan mudah diserap oleh tanaman padi. Oleh karena itu, penelitian bertujuan untuk menginvestigasi kelayakan kondisi tanah sawah untuk budidaya padi. Untuk medapatkan hasil analisis yang akurat, proses identifikasi kondisi tanah dilakukan dengan bantuan teknologi microcontroller dan sensor, yaitu sensor DS18B20 untuk mengukur suhu dan sensor pH tanah. Kemudian untuk menginvestigasi kondisi tanah, data suhu dan $\mathrm{pH}$ yang diperoleh diintegrasi dan dikalkulasi menggonakan kosep logika fuzzy. Hasil penelitian ini menunjukan bahwa sensor yang diterapkan dapat menginterpretasikan kondisi suhu dan $\mathrm{pH}$ tanah sesuai dengan kondisi nyata dengan tingkat akurasi untuk sensor suhu 96,67\% dan akurasi sensor pH sebesar 97,00\%. Selain itu, logika fuzzy yang diterapkan juga dapat digunakan untuk mengklasifikasikan kondisi tanah sawah ke dalam kategori tidak baik, kurang baik, dan baik.
\end{abstract}

Kata Kunci: Kesuburan Tanah; Microcontroller; Sensor; Fuzzy

\begin{abstract}
[Title: Implementation of Fuzzy Logic as a Determinant of Paddy Soil Quality based on pH and Temperature] The fertility is one of the critical factors that can affect rice growth. As higher the level of soil fertility, the success of rice cultivation will increase. Nevertheless, there are several factors causing the low productivity of paddy. However, among these factors, these temperature and $p H$ are the two main factors causing the failure of rice cultivation. The temperature is very influential to the growth of pests, while the $\mathrm{pH}$ serves so that nutrients in the soil can be easily absorbed by paddy. Therefore, this study aims to investigate the feasibility of the paddy field condition. To obtain accurate analysis results, the process of identifying soil condition was carried out with microcontroller and sensor technology, which are the DS18B20 sensor to measure temperature and soil pH sensor. Then to investigate soil conditions, obtained temperature and $\mathrm{pH}$ was integrated and calculated using fuzzy logic. The results of this study indicated that sensors applied can interpret the temperature and $\mathrm{pH}$ of the soil in accordance with real conditions with an accuracy $96,67 \%$ and temperature sensor 97,00\%. In addition, the fuzzy logic can also be used to classify the condition of soil into some categories, which are bad, poor, and good soil.
\end{abstract}

Keywords: Soil Fertility; Microcontroller; Sensors; Fuzzy Logic

\section{PENDAHULUAN}

Kesuburan tanah sawah sangat penting dalam bercocok tanam. Faktor kesuburan tanah sangat menentukan keberhasilan dalam budidaya pertanian maupun perkebunan, jika lahan pertanian memiliki tingkat kesuburan tinggi maka keberhasilan budidaya akan tercapai. Adapun masalah dari rendahnya produktivitas tanaman diduga disebabkan oleh beberapa faktor, diantaranya cara pengelolaan lahan yang kurang baik yang berakibat terhadap menurunnya tingkat kesuburan fisik, kimia, dan biologi tanah (Sumarni, Rosliani, \& Duriat, 2010).
Faktor fisika pada tanah meliputi suhu, konsistensi tanah, top soil tanah dan tekstur tanah, sedangkan faktor kimia tanah meliputi $\mathrm{pH}$ tanah (Rahmawati, 2016). Pada umumnya unsur hara akan mudah diserap tanaman pada $\mathrm{pH}$ 6-7, karena pada $\mathrm{pH}$ tersebut sebagian besar unsur hara akan mudah larut dalam air. Derajat pH dalam tanah juga menunjukkan keberadaan unsur-unsur yang bersifat racun bagi tanaman. Jika tanah masam akan banyak ditemukan unsur alumunium $(\mathrm{Al})$ yang selain meracuni tanaman juga mengikat phosphor sehingga tidak bisa diserap tanaman (Martin, Susanto E., \& Sunarya, 2015). Sedangkan suhu sangat berpengaruh terhadap 
pertumbuhan hama, populasi hama P.oryzae sangat dipengaruhi oleh suhu. Suhu rendah adalah faktor paling dominan yang mempengaruhi laju ledakan infeksi penyakit. Populasi $P$. oryzae yang lebih tinggi menyebabkan intensitas ledakan penyakit pada tanaman padi semakin tinggi (Sopialena \& Palupi, 2017), paramaeter-parameter tersebut sangatlah penting untuk dipantau agar kesuburuan tanah dapat terjaga serta dapat meningkatkan produktivitas. Semakin berkembangnya instrumentasi dan sistem kendali sangat memungkinkan untuk dapat diterapkan pada industri pertanian, agar parameterparameter tersebut dapat dikontrol.

Salah satu metode yang dapat digunakan untuk mengontrol sensor DS18B20 dan sensor pH dengan menggunakan microcontroller adalah logika fuzzy. Logika fuzzy banyak diterapkan dalam bidang kontrol otomatis dan industri, karena proses kendali relatif mudah dan fleksibel dirancang dengan tidak melibatkan model matematis yang rumit dari sistem yang akan dikendalikan, logika fuzzy telah berhasil diterapkan dalam penelitian pengaturan $\mathrm{pH}$ nutrisi pada system hidroponik (Pancawati, 2016), berhasil diterapkan pula pada sistem Penanganan Dini Kebocoran LPG dengan nilai error $0,327 \%$ (Iswahyuningsih, Aryansyah, \& Isnawaty, 2015).

\section{METODE}

Metode yang digunakan dalam penelitian ini yaitu menggunakan fuzzy logic pada microcontroller Arduino Mega 2560.

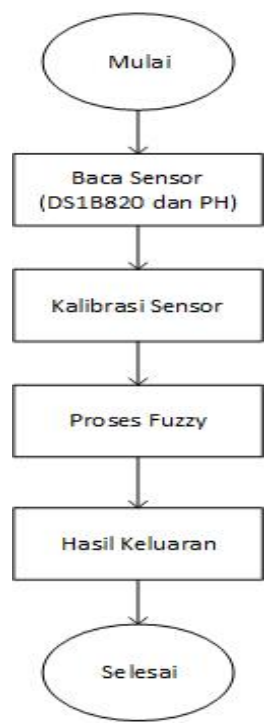

Gambar 1. Flowchart keseluruhan penelitian

Sensor yang digunakan dalam penelitian yaitu sensor DS1B820 dan sensor $\mathrm{pH}$. Proses yang pertama adalah menginisialisasi komponen, kemudian Arduino membaca nilai analog dari port yang terhubung. Dari data analog yang telah diterima, nilai tersebut dikonversi ke

dalam bentuk digital. Kalibrasi setiap sensor dilakukan dengan membandingkan hasil output sensor dengan dengan alat ukur pabrikan yang sudah terstandarisasi yaitu soil survey instrument 4 in 1 .

Untuk menghitung nilai error sensor digunakan persamaan:

$\%$ error $=\left|\frac{x \quad y}{x}\right| \cdot 100$

Keterangan:

$\mathrm{x}=$ nilai soil survey instrument

$y=$ nilai dari alat yang dibuat

$$
A=1-\left|\frac{Y_{n}-X_{n}}{X_{n}}\right|
$$

Keterangan:

$$
\begin{aligned}
& \mathrm{A}=\text { Akurasi } \\
& \mathrm{Yn}=\text { nilai soil survey instrument } \\
& \mathrm{Xn}=\text { nilai dari alat yang dibuat }
\end{aligned}
$$

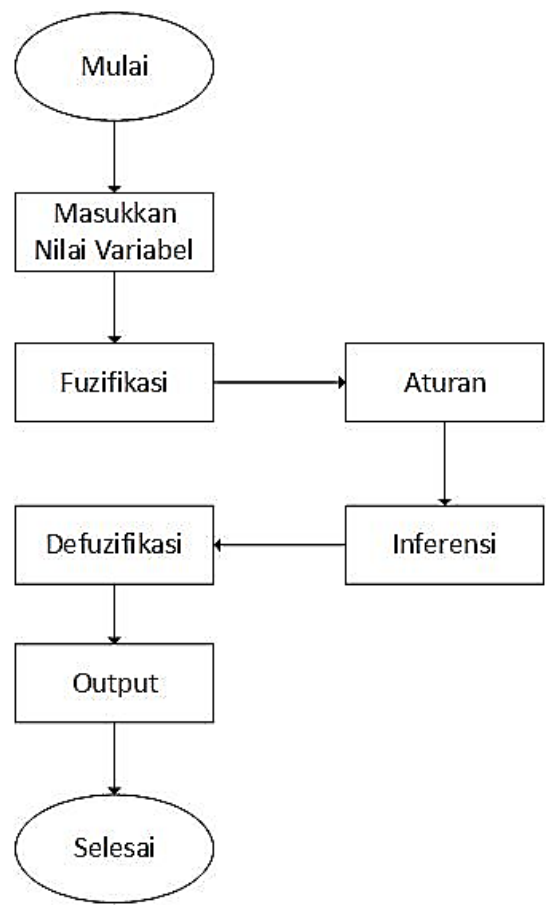

Gambar 2. Flowchart alur program Fuzzy logic

Proses fungsi fuzzy dimulai dengan mendapatkan nilai input dari variabel. Nilai tersebut kemudian digunakan untuk proses fuzzifikasi sehingga menghasilkan derajat keanggotaan dari masingmasing variabel. Fuzifikasi yaitu memetakan nilai crisp 
ke dalam himpunan fuzzy dan menentukan derajat keanggotaannya didalam himpunan fuzzy. Pada sistem yang dikembangkan terdapat dua variabel yang digunakan sebagai input yaitu variabel suhu dan $\mathrm{pH}$.

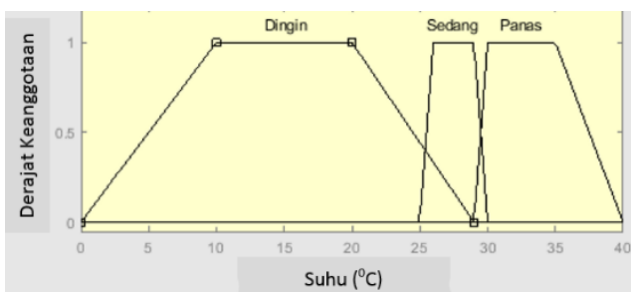

Gambar 3. Variabel input suhu

Variabel suhu dengan semesta pembicaraan mulai dari $0^{\circ} \mathrm{C}$ sampai dengan $40^{\circ} \mathrm{C}$, variabel suhu terbagi menjadi 3 diantaranya adalah tidak aman $\left[0^{\circ} \mathrm{C}\right.$ $\left.10^{\circ} \mathrm{C} 20^{\circ} \mathrm{C} 29^{\circ} \mathrm{C}\right]$, kurang aman $\left[25^{\circ} \mathrm{C} 26^{\circ} \mathrm{C} 28^{\circ} \mathrm{C}\right.$ $\left.30^{\circ} \mathrm{C}\right]$ dan aman $\left[29^{\circ} \mathrm{C} 30^{\circ} \mathrm{C} 35^{\circ} \mathrm{C} 40^{\circ} \mathrm{C}\right]$. Variabel $\mathrm{pH}$ dengan semesta pembicaraan mulai dari kondisi

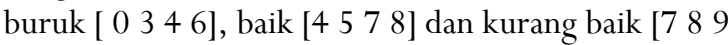
$10]$.

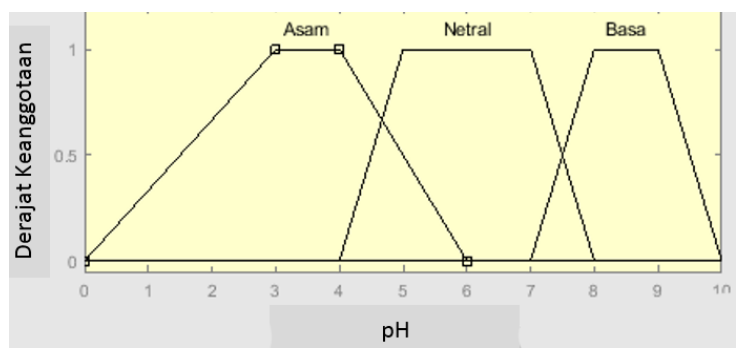

Gambar 4. Variabel input $\mathrm{pH}$

Basis pengetahuan adalah rule yang dibuat untuk mendapatkan output kondisi, adapun kondisi yang akan muncul di LCD yaitu: Kondisi buruk, kondisi kurang aman dan kondisi baik.

Rule 1

IF Suhu $=$ Dingin And $\mathrm{pH}=$ Asam Then Kondisi

$=$ Tidak baik

Rule 2

IF Suhu $=$ Dingin And $\mathrm{pH}=$ Netral Then Kondisi

$=$ Kurang Baik

Rule 3

IF Suhu $=$ Dingin And $\mathrm{pH}=$ Basa Then Kondisi $=$ Tidak baik

Rule 4

IF Suhu $=$ Sedang And $\mathrm{pH}=$ Asam Then Kondisi

$=$ Tidak baik

Rule 5

IF Suhu $=$ Sedang And $\mathrm{pH}=$ Netral Then Kondisi

$=$ Kurang Baik

Rule 6
IF Suhu $=$ Sedang And $\mathrm{pH}=$ Basa Then Kondisi

$=$ Kurang Baik

Rule 7

IF Suhu $=$ Panas And $\mathrm{pH}=$ Asam Then Kondisi $=$ Buruk

Rule 8

IF Suhu $=$ Panas And $\mathrm{pH}=$ Netral Then Kondisi

$=$ Baik

Rule 9

IF Suhu $=$ Panas And $\mathrm{pH}=$ Basa Then Kondisi $=$ Kurang Baik

Proses selanjutnya yaitu Defuziffikasi menggunakan metode centroid, solusi crispt diperoleh dengan cara mengambil titik pusat $\left(Z^{*}\right)$ daerah Fuzzy.

$$
\mathrm{Z}^{*}=\frac{\int \mu_{x} z(d z)}{\int \mu_{x}(d z)}+
$$

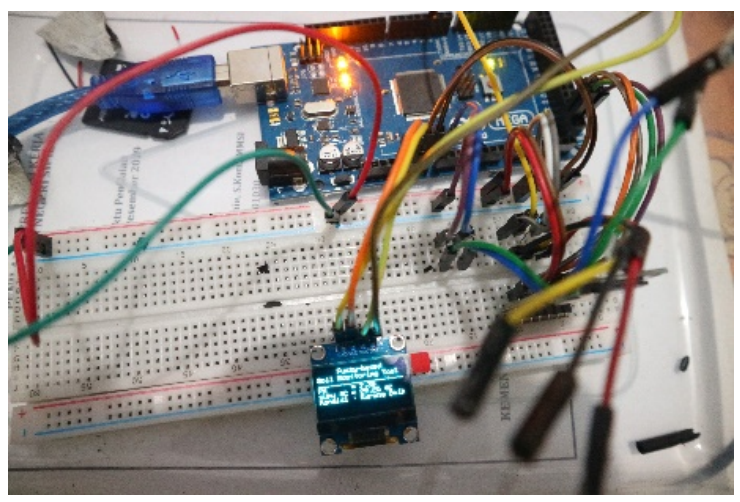

Gambar 5. Rangkaian keseluruhan

\section{HASIL DAN PEMBAHASAN}

Pada rangkaian Gambar 5, digunakan microcontroller Arduino mega 2560, sensor suhu memiliki 3 pin yaitu pin 1 ke $V_{c c}$, pin 2 ke pin 2 dan pin 3 ke ground. Sensor $\mathrm{pH}$ memiliki 2 pin, pin 1 ke pin Ao pin 2 ke ground. SD card memiliki 6 pin, miso ke pin 50, mosi ke pin 51, SCK ke pin 52, Cs ke pin 53, VCc ke 5volt dan ground ke pin ground Arduino. LCD oled blue memiliki 4 pin, pin gnd ke ground, pin vdd ke pin vcc 5 volt, SCK ke pin 21 dan SDA ke pin 20. 
Sensor yang digunakan yaitu sensor $\mathrm{pH}$ tanah dan sensor suhu (DS18B20) dengan alat pembanding yang sudah terstandarisasi yaitu soil survey 4 in 1 .

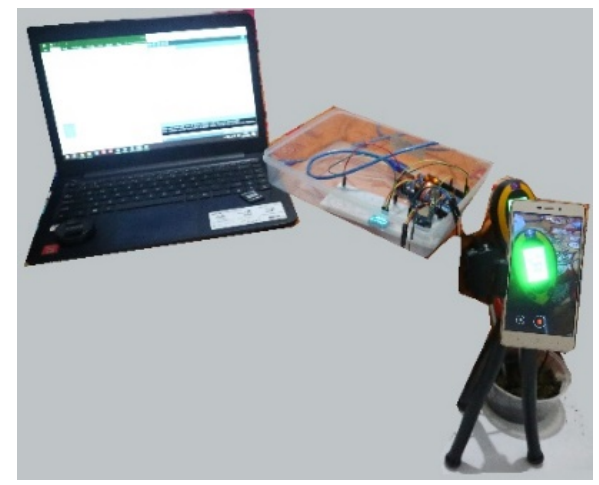

Gambar 6. Uji sensor

Alat pembanding yang digunakan harus dicatat secara manual maka untuk mempermudah pengambilan data dibantu dengan kamera untuk merekam.

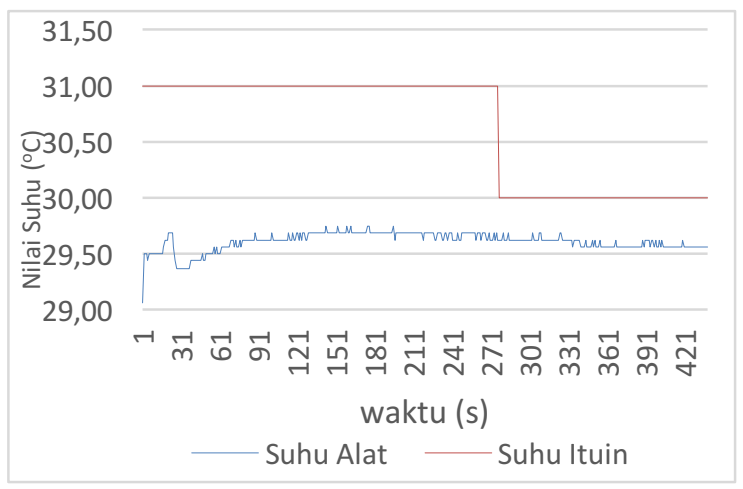

Gambar 7. Perbandingan nilai Suhu

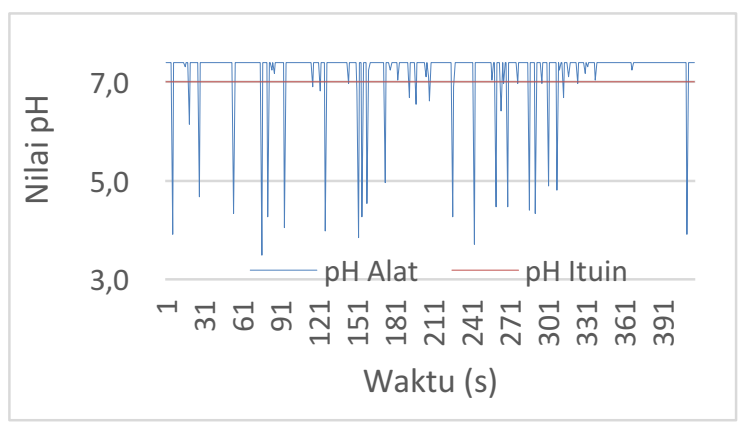

Gambar 8. Perbandingan nilai $\mathrm{pH}$

Perbandingan dua data yang diperoleh dari data sensor suhu serta dari alat soil survey 4 in 1 . Dengan data uji sebanyak 438 data. Perhitungan error dihitung dengan menggunakan persamaan (1) maka didapatkan nilai error untuk sensor suhu sebesar 3,3
$\%$ dan nilai akurasi yang diperoleh dengan persamaan (2) yaitu 96, $67 \%$.

Gambar 8 yaitu perbandingann nilai yang didapat menggunakan sensor $\mathrm{pH}$ dan soil survey 4 in 1. Dengan perhitungan menggunakan persamaan (1) didapatkan nilai error sebesar 3,01 \%. Dan perhitungan akurasi menggunakan persamaan (2) diperoleh 97\%.

Proses fungsi fuzzy dimulai dengan mendapatkan nilai input dari variabel. Nilai tersebut kemudian digunakan untuk proses fuzzifikasi sehingga menghasilkan derajat keanggotaan dari masingmasing variabel. Nilai derajat keanggotaan dari setiap variabel dimasukkan pada aturan (Rule) yang telah dibuat dan dicari nilai minimal. Proses yang terakhir adalah Defuzzifikasi. Dari nilai (Max dan Min) kemudian diproses deffuzifikasi sehingga menghasilkan output yang akan ditampilkan pada monitor LCD.

Variabel suhu dibagi menjadi 3 kondisi yaitu:

Dingin $\left[0^{\circ} \mathrm{C} 10^{\circ} \mathrm{C} 20^{\circ} \mathrm{C} 29^{\circ} \mathrm{C}\right]$,

$>$ Sedang $\left[25^{\circ} \mathrm{C} 26^{\circ} \mathrm{C} 28^{\circ} \mathrm{C} 30^{\circ} \mathrm{C}\right]$

$>$ Panas $\left[29^{\circ} \mathrm{C} 30^{\circ} \mathrm{C} 35^{\circ} \mathrm{C} 40^{\circ} \mathrm{C}\right]$.

Sedangkan variabel $\mathrm{pH}$ menjadi 3 kondisi yaitu:

Asam [ $\left.\begin{array}{llll}0 & 3 & 4 & 6\end{array}\right]$

Netral [ [ $\left.\begin{array}{llll}4 & 5 & 7 & 8\end{array}\right]$

Basa [7 89 10]

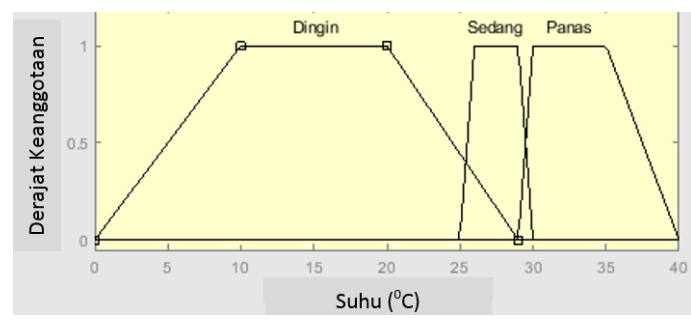

Gambar 9. Variabel input suhu

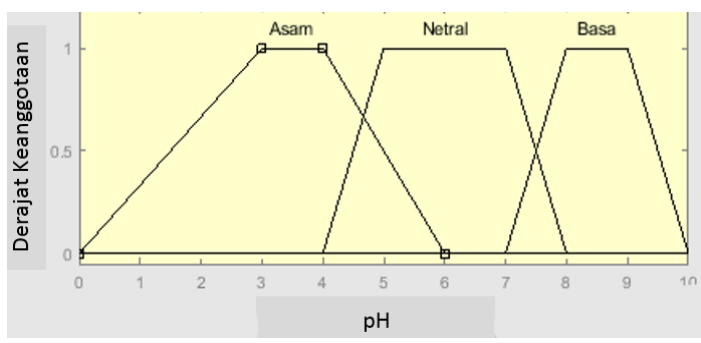

Gambar 10. Variabel input $\mathrm{pH}$

Rule yang dibuat pada program terdiri dari 9 rule:

Rule 1 
IF Suhu $=$ Dingin And $\mathrm{pH}=$ Asam Then Kondisi

$=$ Tidak baik

Rule 2

IF Suhu $=$ Dingin And $\mathrm{pH}=$ Netral Then

Kondisi $=$ Kurang Baik

Rule 3

IF Suhu $=$ Dingin And $\mathrm{pH}=$ Basa Then Kondisi

= Tidak baik

Rule 4

IF Suhu $=$ Sedang And $\mathrm{pH}=$ Asam Then

Kondisi $=$ Tidak baik

Rule 5

IF Suhu $=$ Sedang And $\mathrm{pH}=$ Netral Then

Kondisi $=$ Kurang Baik

Rule 6

IF Suhu $=$ Sedang And $\mathrm{pH}=$ Basa Then Kondisi

$=$ Kurang Baik

Rule 7

IF Suhu $=$ Panas And $\mathrm{pH}=$ Asam Then Kondisi

$=$ Buruk

Rule 8

IF Suhu $=$ Panas And $\mathrm{pH}=$ Netral Then Kondisi

$=$ Baik

Rule 9

IF Suhu $=$ Panas And $\mathrm{pH}=$ Basa Then Kondisi

$=$ Kurang Baik

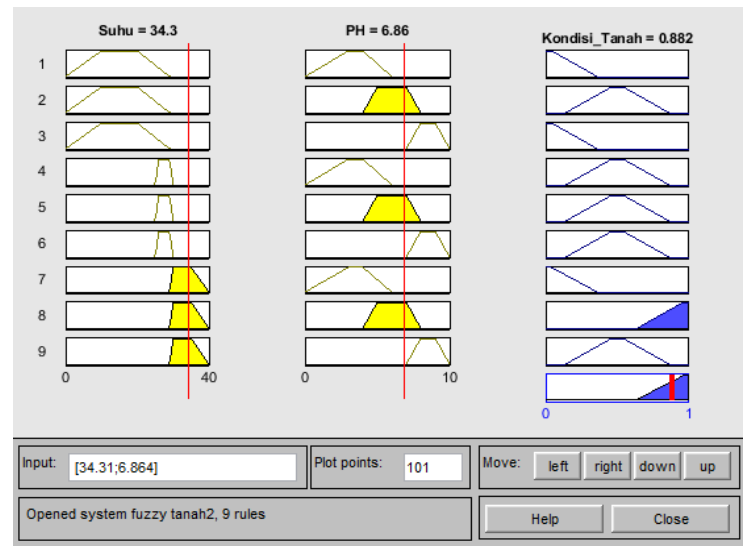

Gambar 11. Simulasi aturan fuzzy

Pada gambar 11 diberikan simulasi dengan nilai suhu $34,3^{\circ} \mathrm{C}$ dan nilai $\mathrm{pH}$ 6,86 maka didapatkan nilai defuzifikasi dalam derajat keanggotaan yaitu 0,882 . Maka berdasarkan nilai output, hasil proses fuzzy berada dalam derajat keanggotaan 0,882 yang berarti dalam kondisi baik.

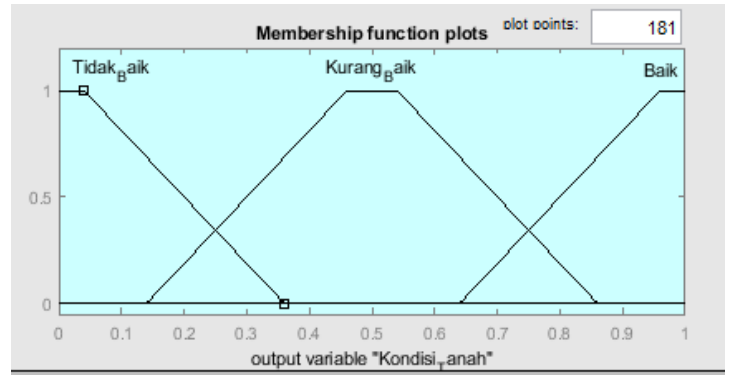

Gambar 12. Output proses fuzzy

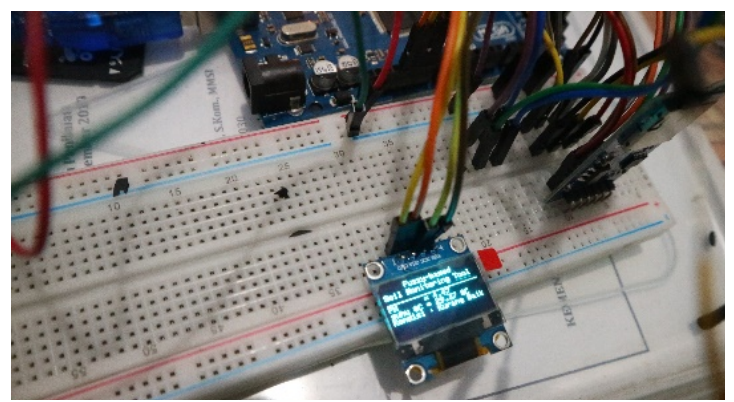

Gambar 13. Output kondisi pada sistem

Gambar 13 adalah output hasil proses fuzzy dengan tiga kondisi tanah yang ditampilkan menggunakan LCD.

\section{KESIMPULAN DAN SARAN}

Sensor pH tanah dan sensor suhu DS18B20 dapat berfungsi dengan baik dalam mengukur suhu dengan nilai akurasi sebesar 96,67\% dan akurasi untuk sensor $\mathrm{pH}$ tanah sebesar $97 \%$.

Algoritma fuzzy dapat diterapkan untuk mengetahui kondisi tanah dari parameter-parameter fisis maupun kimia sebagai input. Saran untuk penelitian selanjutnya agar menambahkan variabelvariabel sebagai input proses fuzzy.

\section{UCAPAN TERIMAKASIH}

Penelitian ini didanai dari Hibah LPPM Universitas Singaperbangsa Karawang tahun 2019. Oleh karena itu Penulis mengucapkan terimakasih kepada LPPM Universitas Singaperbangsa Karawang dan juga pihak-pihak terkait yang telah mendukung kami dalam penyelesaian penelitian ini.

\section{DAFTAR PUSTAKA}

Iswahyuningsih, A., Aryansyah, K., \& Isnawaty. (2015). Penerapan Logika Fuzzy pada Sistem Penanganan Dini Kebocoran LPG dengan Antarmuka Web dan SMS Gateway . fortei, 161-166.

Martin, J., Susanto E., \& Sunarya, U. (2015). KENDALI PH DAN KELEMBABAN TANAH BERBASIS LOGIKA FUZZY 
MENGGUNAKAN MICROCONTROLLER . e-Proceeding of Engineering : Vol.2, No.2, 2236-2245.

Pancawati, D. Y. (2016). Implemenatsi Fuzzy Logic Controller Untuk Mengatur pH Nutrisi Pada Sistem Hidroponik Nutrient Film Technique (NFT). Jurnal Nasional Teknik Elektro, 276-289.

Rahmawati, I. (2016). PENGARUH FAKTOR FISIKA DAN KIMIA TANAH TERHADAP INDEKS KEANEKARAGAMAN HEWAN TANAH. Pekanbaru: Program Studi Pendidikan Biologi Jurusan PMIPA FKIP.
Sopialena, \& Palupi, J. (2017). Study of climatic factors on the population dynamics of Pyricularia oryzae on some varieties of paddy rice (Oryza sativa) . BIODIVERSITAS, 701-708.

Sumarni, N. R., Rosliani, \& Duriat, A. (2010). Pengelolaan Fisik, Kimia, dan Biologi Tanah untuk Meningkatkan Kesuburan Lahan dan Hasil Cabai Merah. J. Hort, 130-137. 